\title{
Regional Convergence in Chile: New Tests, Old Results*
}

\author{
ROBERTO DUNCAN \\ University of Wisconsin \\ RODRIGO FUENTES \\ Banco Central de Chile
}

Convergence tests implicitly test the unit root hypothesis for per capita income. Although the statistics do not have critical values under the null hypothesis most papers on this subject use them, with the corresponding problems for inference. This paper determines the existence of convergence in GDP levels and income across the regions of Chile using the traditional tests and also recent unit root tests for panel data that allow for correct inferences. We also analyze convergence in dispersion, evaluating the presence of asymmetries or the formation of regional "clubs" using nonparametric tests. Our main conclusions are: (1) the evidence supports the hypothesis of absolute $\beta$ convergence in both per capita GDP and income; (2) the convergence rate is higher for income than for GDP; (3) the conditional convergence rate increases when we control for the share of mining on the regional productive structure; (4) the data do not support the existence of convergence clubs; and (5) there is no clear evidence of $\sigma$ convergence.

JEL: O18, O40, N16, R11

Keywords: Convergence, Economic Growth, Panel Data, Unit Root Tests, Asymmetries, Growth Clubs, Chile.

\footnotetext{
*We thank Rómulo Chumacero, José de Gregorio, Pablo García and two anonimous referees for commenting on an earlier version of this paper, Fabián Gredig who generously provided us with the code for testing bimodality, and Osvaldo Larrañaga, Jeanette Fuentes and Amalia Palma for providing some of the data. The views expressed herein are those of the authors and are not necessarily shared by the Central Bank of Chile or its Board.

E-mails: duncantaraba@wisc.edu,rfuentes@bcentral.cl.
} 


\section{INTRODUCTION}

Traditional convergence tests implicitly evaluate the unit root hypothesis in per capita output series. Although these statistics do not have asymptotic distributions or critical standard values under the null hypothesis, the great majority of works on the subject uses them, with the corresponding problems for inference. For this reason, new tests have been developed in the literature on panel data estimation to analyze the convergence hypothesis correctly. The goal of this paper is to determine if the existing relatively weak evidence that favor the hypothesis of convergence of GDP and income among the regions of Chile holds when such new tests are applied and a more recent database is used. The analysis is conducted using not only the traditional tests (cross-section and panel data), but also the most recent unit root tests developed for panel data, which allow making correct inference. We also analyze convergence in dispersion, constructing confidence intervals for the variance of regional production and income and evaluating the presence of asymmetries or the formation of regional "clubs" through a nonparametric multimodality test.

The theoretical foundation for the empirical analysis is framed within neoclassic growth theory, which attempts to explain whether the different economies converge to a single distribution of per capita output or income levels. In our analysis, these economies are the thirteen regions of Chile, and the time frame is 1960-2000. The implication of this literature is that per capita GDP is trend stationary as a contraposition of the endogenous growth literature, which predicts that this series would be difference stationary. The latter means that temporary shocks will have a permanent effect on the level of GDP, while in the case of the neoclassical model, temporary shocks willl have a temporary effect on the level of this variable. Therefore, the stochastic process that underlies the per capita GDP series is a key element for discriminating beween these two theories.

The earliest works analyzing the dynamics of regional GDP per capita in Chile find that there is, in fact, convergence in per capita GDP levels, but that the speed or rate of unconditional convergence is relatively slow: 1.3\% for the 196090 period (Fuentes, 1997) and 1.2\% for the 1960-92 period (Morandé, Soto and Pincheira, 1997). A later analysis (Anríquez and Fuentes, 2001) shows that the speed is higher for income $(8.9 \%)$ than GDP $(1.3 \%)$, based on data from the National Socioeconomic Characterization (CASEN) survey for the 1987-1994 period. More recent studies find that this convergence rate fluctuates between $0.5 \%$ (Soto and Torche, 2004) and 1.0\% (Díaz and Meller, 2004). Relatively few works find divergence among the Chilean economies. Some of them only find convergence in certain groups or "clubs" of regions, reporting, for example, that all regions converge except the Metropolitan and II regions (Díaz and Herrera, 1999) or that convergence occurs in all but the I, II, and XII regions (Araya and Oyarzún, 2001).

One of the valid critiques of the empirical focus used in the majority of the previous works is that by regressing the per capita GDP growth rate (expressed 
as the change in the log of the level) and its initial level, the analyst is using the typical unit root test (augmented Dickey-Fuller) to estimate coefficients of convergence speeds whose $t$ test, under the null hypothesis, does not have a standard distribution (see Chumacero, 2002, and references therein). Consequently, making inference based on these regressions using the traditional statistics and associated critical values can lead to erroneous results.

This paper differs from previous works in three ways. First, we analyze the growth of regional economic activity using a more updated database that includes -in contrast to the other cases- regional GDP for the 1960-2000 period, with figures recently published by the Central Bank, and data on household income for 1987-2000, from the CASEN survey. We are thus able to capture the recent period of strong turbulence and external crisis (1997-2000) and to observe their potential effects on regional convergence. Second, we use unit root tests recently developed for panel data to evaluate the null hypothesis of the absence of convergence and avoid the problems of inadequate inference mentioned above. To contrast the results, we include estimates and tests of the convergence hypothesis using traditional cross-section and panel data techniques. Third, we use a nonparametric multimodality test to evaluate the presence of regional asymmetries or "clubs" and thus verify whether the apparent bimodality of the empirical distributions is statistically significant.

The remainder of the paper is organized in four sections. The next section (section 2) briefly and intuitively explains the ideas of beta and sigma convergence. Section 3 then describes the construction, periods, frequency and sources of the data used in the estimations. Section 4 outlines the empirical strategy followed and presents our main results. Finally, section 5 concludes.

\section{Convergence Theory}

The fundamental paradigm of economic convergence stems from the Solow (1956) and Swan (1956) model, which was later formalized in a dynamic optimization framework by Cass (1965) and Koopmans (1965). This model predicts that, given an initial stock of capital per worker, an economy converges to a long-run (steady-state) equilibrium in which the output per worker grows at a constant rate equal to the rate of technical change. In the transition, the economy grows above the long-run rate and closes the gap with that rate asymptotically. This generates one of the main implications of the model -namely, that in the steady-state equilibrium, the per capita income of different economies converges to the same level once the savings rate, depreciation rate, and population growth rate are taken into account.

The idea of convergence is also related to the idea that the poorest economy closes the gap with the richest economy in the dynamic transition to the steady state. In other words, the poorest economy grows faster than the richest. In the economic growth model with optimization, an economy's growth rate is an increasing function of the difference between the marginal product of capital 
and the agents' rate of intertemporal impatience. That is, economies with a larger difference grow faster. Poor economies have less capital and, therefore, a higher marginal productivity than richer economies. Thus the growth rate of the poorest economy (or the economy that is positioned farthest from its steady state) is higher. As the economy accumulates capital, marginal productivity falls and, therefore, the growth rate also drops until it finally reaches the rate of technical progress.

There are two concepts of convergence related to this model: beta $(\beta)$ convergence and sigma $(\sigma)$ convergence. ${ }^{1}$

\subsection{Beta Convergence}

Beta $(\beta)$ convergence is said to occur when the poorest economies -which are the furthest from their long-run output or income level-grow faster then the richest economies until they achieve the same level of output. ${ }^{2}$ In other words, $\beta$ convergence is observed when there is a negative relationship between the growth rate of per capita output or income and the initial per capita output level. Formally, this implies finding a negative coefficient for $\beta$ in a linear relationship between the growth rate and the initial level of output.

An issue that is closely linked with testing this hypothesis, and one that we need to address for the empirical analysis below, is the relationship between the type of growth and the type of stochastic process that underlies the output or income series. Modern economic growth theory can be divided in two strands: exogenous growth and endogenous growth. Our analysis and, therefore, our convergence hypothesis are consistent with the exogenous growth approach. ${ }^{3}$ According to exogenous growth models, if positive growth is observed in the long run, then this could be equal to the rate of technological change but independent from economic agents' decisions -as well as from their preferences and, therefore, their savings rates. In contrast, endogenous growth models consider the possibility that agents can affect the long-run growth rate through their saving decisions. The main implication for our analysis is that exogenous growth models predict that temporary changes should have temporary effects on output or income, whereas in the endogenous growth models, temporary changes can have permanent effects. That is, exogenous growth models are generally coherent with trend-stationary series, while endogenous growth models are consistent with difference-stationary series, characterized mainly by unit root processes. Consequently, evidence supporting the presence of stationary trend processes in

\footnotetext{
${ }^{1}$ See Barro and Sala-i-Martin (1995).

${ }^{2}$ For this proposition to hold, preferences (savings rates), technology, depreciation rate, and population growth are assumed equal in both economies. The production function must also show constant returns to scale and fulfill the Inada (1963) conditions.

${ }^{3}$ Note that under certain endogenous growth models with transitional dynamic, it is possible to observe that a poorer economy will grow faster than the the richer one ( $\beta$ convergence). Nevetheless, when both economies reach the steady-state growth rate they will grow at the same speed.
} 
our output and income series is consistent with the predictions of the exogenous growth model, which predict $\beta$ convergence.

\subsection{Sigma Convergence}

Sigma convergence is said to exist when the dispersion of per capita income or output, measured as its variance, diminishes over time. Formally, $\sigma$ convergence is confirmed when the cross-sectional variance of the regional per capital incomes or outputs shows a (statistically) significant decrease between the initial and final periods of the sample. In a world without stochastic shocks, the implicit idea is as follows: in the initial period there is a high dispersion of per capita output -due to the difference between rich and poor regions- that is expected to be lower at the end of the process of convergence toward the steady state.

It can be shown that the existence of $\beta$ convergence is a necessary but not a sufficient condition for the presence of $\sigma$ convergence. In practice, it is thus possible to find that the richest economies or regions grow less than the poorest, but ultimately the dispersion remains unchanged over time. This would be the case if the regions that were initially relatively poor grew faster than the wealthy regions and overtook them, leaving the dispersion of per capita income the same as at the initial period. However, since $\beta$ convergence is a necessary condition, it is not possible to observe $\sigma$ convergence without $\beta$ convergence ${ }^{4}$. Note that $\sigma$ convergence typically implies that the variance of per capita output decreases over time. However, the initial variance converges to its steady-state level, which may be higher or lower than the initial level depending on whether the dispersion of initial per capita output is lower or higher than the steady state, which is, in turn, a function of the shocks experienced by the economies. Beta convergence ensures that the variance will converge to the steady-state level, but it does not say whether the variance diminishes or increases over time.

\subsection{Absolute and Conditional Convergence}

From an empirical perspective, another dimension of economic convergence analysis involves the distinction between absolute (or unconditional) and conditional convergence. Absolute convergence is said to pertain when all the economies converge regardless of economy-specific factors (economic policies, investment rate, composition of output, and so forth); that is, the poorer economies always grow faster than the richer ones. This implicitly requires that the economies have similar population growth rates, preference parameters, and technology. In this sense, there is also a condition for convergence.

Conditional convergence, in turn, occurs when the relation between the growth rate of per capita output and its initial level is negative once we have 
controlled for factors that condition the steady state. In other words, the economies converge only when we take into account the factors that are specific to the steady state toward which they are moving.

\section{THE DATA}

To test the convergence hypothesis on the GDP and income of the thirteen regions of Chile, we use all the data available at the close of this study.

\subsection{Per Capita GDP}

In the case of regional output, the period of analysis is from 1960 to 2000. Figure 1 shows the trends in gross real per capita output levels for each region (expressed in natural logs) during the period.

These series were constructed from two sources. First, in the numerator, we use the Central Bank of Chile's regional GDP series, in millions of 1986pesos for the 1960-96 period, and the growth rates from the new series in millions of 1996-pesos for the rest of the span (that is, 1997-2000). ${ }^{5}$ Second, in the denominator, we use the regional population statistics published annually by the National Institute of Statistics (INE), based on the censuses and the institute's own estimates, on June 30th of each year.

\subsection{Per Capita Income}

In the case of per capita income, the period of analysis is significantly reduced due to data availability. We used the average household income series ${ }^{6}$ for each region for the years 1987, 1990, 1992, 1994, 1996, 1998, and 2000, following the CASEN surveys that are carried out by the Department of Social Information of the Ministry of Planning and Cooperation (MIDEPLAN). We then calculated the nominal per capita income by region using the number of households in each region from each survey and the regional population. To express these series in real terms, we constructed price indexes by region, weighting the prices of a basket of 35 food products based on information provided by INE. ${ }^{7}$

\footnotetext{
${ }^{5}$ This base change in the regional GDP series was taken into account in the convergence estimates presented below.

${ }^{6}$ The average household income includes all the incomes of the members of the house like government transfers net of taxes and an imputed amount for house renting in the case that the household own the house.

${ }^{7}$ We considered the wholesale prices of 35 food products in the capital city of each region for the survey years mentioned. We then constructed indexes averaging these prices using the weights of the CPI basket, with 1998 as the base year. To make incomes compatible across time and among regions, we not only took into account price changes between periods, but also adjusted them relative to the Metropolitan Region's index.
} 


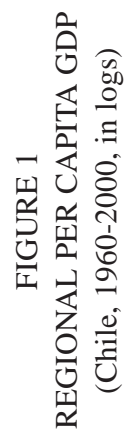

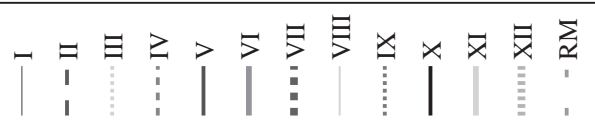

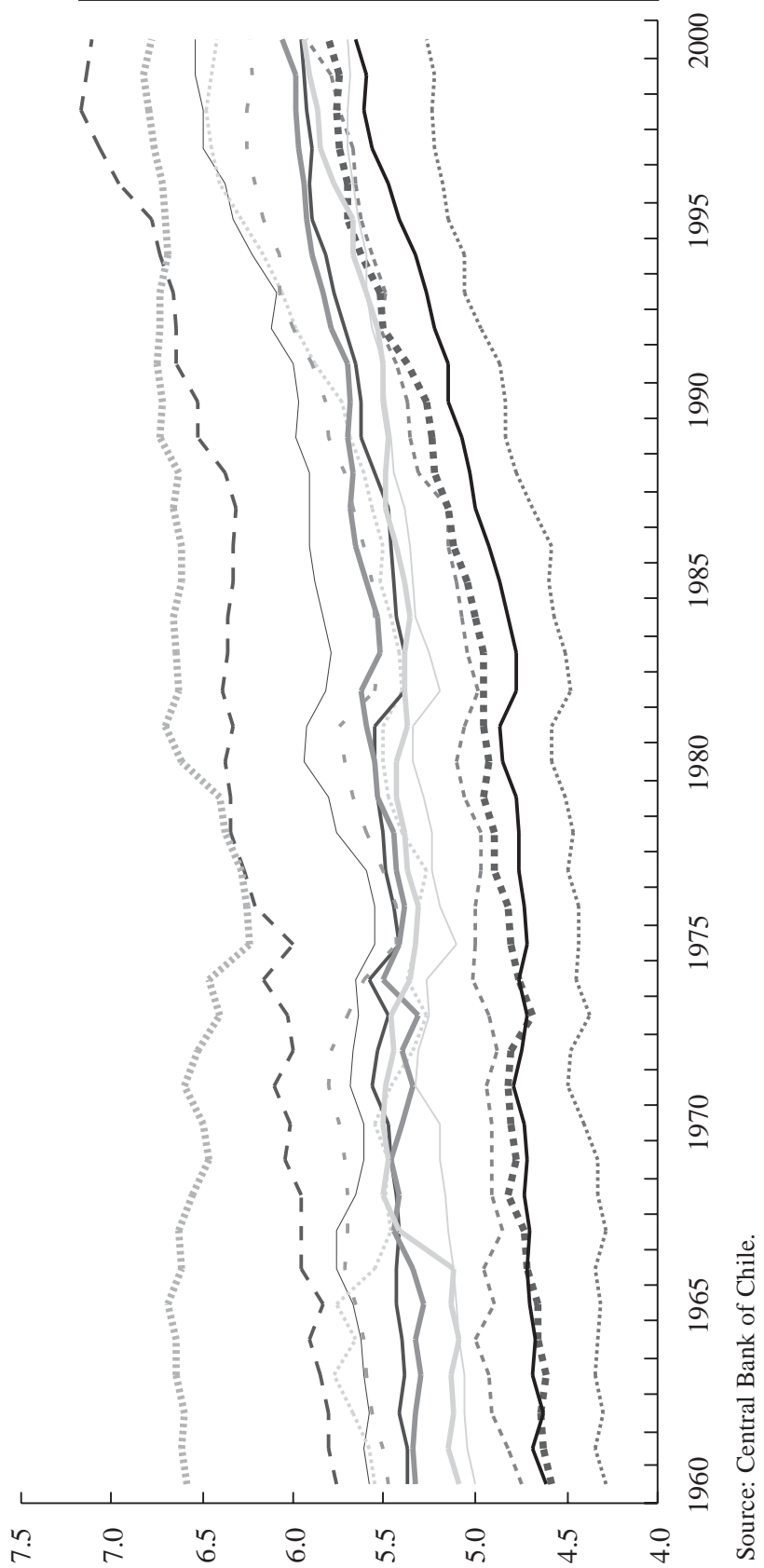


Figure 2 shows the per capita income trend for each region during the available period. ${ }^{8}$

\section{Empirical Strategy and Results}

Following the outline presented above, we first present the empirical tests and their respective results for $\beta$ convergence in both GDP and regional income, and we then assess the case of $\sigma$ convergence.

\subsection{Beta Convergence in Regional GDP}

We first hypothesize whether Chile's regions display absolute convergence in output levels -that is, $\beta$ convergence. In order to present robust estimates and obtain solid conclusions, we then undertake the typical convergence tests through cross-section and pooled panel data regressions, for both GDP and income series. Finally, we apply recent panel data unit root tests that allow us to make correct inference on the hypothesis under study.

\section{Traditional Convergence Tests}

The most commonly used regressions in growth studies are crosssectional. ${ }^{9}$ The basic idea is to estimate the coefficients of the following equation and evaluate the null hypothesis of divergence (that is, $\beta=0$ ) against the alternative hypothesis of convergence, when $\beta \in(-1,0)$ :

$$
\frac{y_{i, T}-y_{i, 0}}{T}=\alpha+\beta y_{i, 0}+u_{i 0}, \quad i=1, \ldots, N
$$

where $y$ is the natural log of output or income, $T$ denotes the number of periods, $\alpha$ is a constant (which captures the regions' steady state), $\beta$ captures the rate or speed of convergence, and $u$ is a disturbance term. Note that here we only consider the growth rate of output in the whole period of analysis (between $t=$ 0 and $T=1) .{ }^{10}$

The first evidence in favor of this hypothesis is presented in Figure 3, which shows the negative relationship between the growth rate (from 1960 to

\footnotetext{
${ }^{8}$ We must warn that we are careful how we interpret the results from estimations based on these series because of the limited quality of the sources. First, our main source for constructing regional income is a household survey that -aside from the conventional measurement error- has been subject to methodological changes through time. Second, the price index is only a proxy of what, strictly speaking, must be a consumer price index for each region.

${ }^{9}$ See, for example, Baumol (1986).

${ }^{10}$ Strictly speaking, we should estimate the nonlinear version of equation 1 . However, we opted for this simpler specification because the econometric results are very similar and the specification allows us to use panel data unit root tests, as explained below.
} 


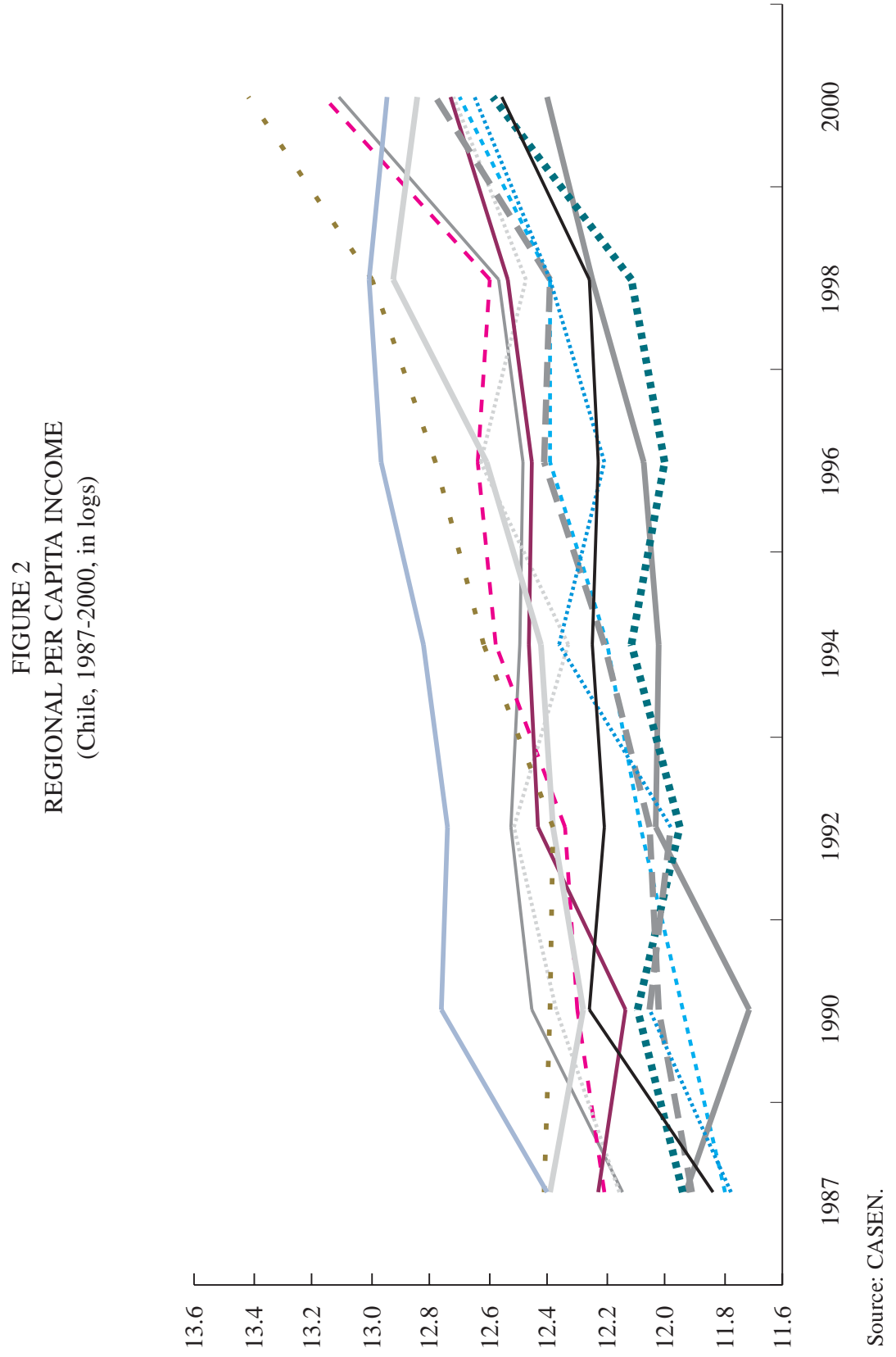

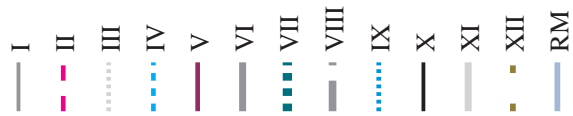


FIGURE 3

AVERAGE GROWTH RATE AND INITIAL PER CAPITA GDP

(Chile, 1960-2000)

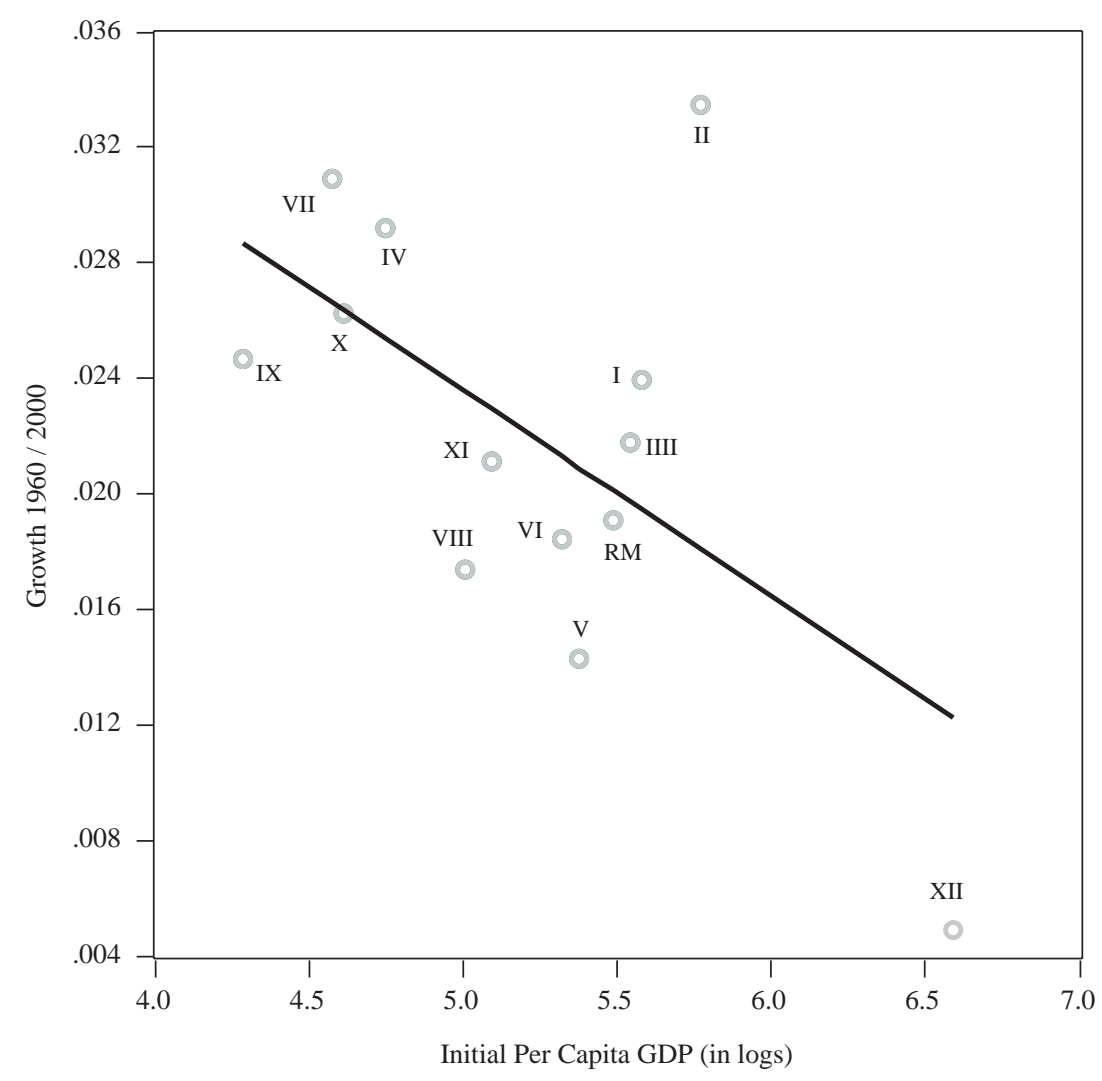

2000) and the initial level of regional GDP per capita (in 1960). The estimated coefficient in this regression is negative, as expected, and statistically significant. ${ }^{11}$ The convergence rate is $0.72 \%$ (see Table 1). To get an idea of the speed (in years) with which this convergence should take place, we calculated the half-life for closing the gap between the GDP per capita of the relatively poorer regions and the relatively richer ones. In this case, the convergence rate implies that half the gap should be closed in 96.8 years (see Table 1).

This approach is limited, however, for making sufficiently valid inference because of the scarcity of observations (only thirteen, the number of regions); this limitation is of particular concern considering that the number of regions in

${ }^{11}$ We used White's (1980) covariance matrix estimator to avoid inference problems in the face of the probable presence of heteroskedastic errors. 
TABLE 1

TRADITIONAL TESTS FOR $\beta$ CONVERGENCE IN GDP: CROSS-SECTION AND POOLED PANEL DATA ${ }^{\mathrm{a}}$

\begin{tabular}{|c|c|c|c|}
\hline \multirow{2}{*}{ Coefficient } & \multicolumn{3}{|c|}{ Convergence in GDP } \\
\hline & Cross-section $^{b}$ & Ten-year pool ${ }^{\mathrm{C}}$ & Five-year pool $^{c}$ \\
\hline$\beta$ & $\begin{array}{c}-0.00716 \\
(0.0035) \\
{[0.0627]}\end{array}$ & $\begin{array}{c}-0.00736 \\
(0.0034) \\
{[0.0343]}\end{array}$ & $\begin{array}{c}-0.00852 \\
(0.00412) \\
{[0.0410]}\end{array}$ \\
\hline \multicolumn{4}{|l|}{ Statistics } \\
\hline$R^{2}$ & 0.33216 & 0.549739 & 0.573818 \\
\hline$F$ statistic & 5.471203 & 14.34595 & 15.98868 \\
\hline$P$ value & 0.039237 & 0.000000 & 0.000000 \\
\hline No. observations & 13 & 52 & 104 \\
\hline $\begin{array}{l}\text { Years to close half } \\
\text { the gap }{ }^{d}\end{array}$ & 96.8 & 94.2 & 81.4 \\
\hline
\end{tabular}

a. Series: regional GDP per capita (1960-2000). Standard deviations are in parentheses; $p$ values are in brackets.

b. White covariance matrix estimator was used.

c. White covariance matrix estimator was used. Time effects were included; fixed or random effects were not.

d. Calculated as $\ln (1 / 2)$ divided by the respective beta coefficient.

a country is always small and finite. An alternative approach proposed in the literature is to test the $\beta$ convergence hypothesis via the panel data technique, estimating an equation similar to the previous one: ${ }^{12}$

$$
\frac{y_{i, t}-y_{i, t-1}}{T}=\alpha+\beta y_{i, t-1}+u_{i, t}
$$

where, in this case, $T$ denotes the number of periods or years between $t$ and $t-1 .^{13}$

One of the advantages of this technique is that it lets us take advantage not only of the cross-sectional dimension, but also of the time dimension, thus providing greater degrees of freedom. ${ }^{14}$

In the case of absolute convergence, we chose a pooled panel instead of fixed or random effects mainly because assuming the presence of unobserved idiosyncratic effects (whether fixed or stochastic) would be equivalent to assuming

\footnotetext{
${ }^{12}$ See, for example, Barro and Sala-i-Martin $(1991,1992)$.

${ }^{13}$ If, for example, we are analyzing a ten-year panel, the number of periods between $t$ and $t-1$ is $T=10$.

${ }^{14}$ For the ten-year panel, the number of temporal observations is four, whereas it is eight with the five-year panel.
} 
that each region's output or income converges to a different stationary level, or that they converge conditional on controlling for exogenous components specific to each region. Consequently, this alternative is particularly valid when dealing with conditional convergence, an issue we address below. On the other hand, we do include temporal effects common to all the regions, basically to control for the potential effects of the base change in the regional GDP series in 1997 and the change in methodologies in the different CASEN surveys. The inclusion of the temporal effects does not invalidate the hypothesis of absolute convergence to the extent that it is consistent with the series being trend stationary, which in turn is coherent with the type of growth model we are employing, as was explained in section 2.1 .

Thus if we estimate the coefficients that relate the ten- or five-year growth rate with the respective initial output levels, we obtain values of -0.74 and -0.85 percent, respectively (see table 1a). Once again the values are negative and statistically significant, which implies a process of regional convergence in GDP. ${ }^{15}$ In this case, half the gap should close in approximately 81 to 94 years.

These estimated values for the GDP convergence coefficient are, at nearly $-1 \%$, lower than the levels found in earlier studies on both regional convergence in Chile and developed countries (around 2\%). ${ }^{16}$ However, they are similar to the findings of more recent works (close to $1 \%$ as in Díaz and Meller, 2004; and close to $0.5 \%$ as in Soto and Torche, 2004). This suggests that while per capita GDP is converging, the process has slowed somewhat in recent years.

\section{Unit Root Tests}

A valid criticism of regressions between the per capita GDP growth rate and initial per capita GDP is that the test does not have a standard distribution under the null hypothesis $(\beta=0)$, so making a comparison using the traditional statistics and related critical values can lead to erroneous conclusion. ${ }^{17}$ Essentially, the test in question does not have a Student's $t$ distribution under the null hypothesis, but rather constitutes an augmented Dickey-Fuller unit-root test for panel data, similar to equation $2:^{18}$

$$
\Delta y_{i, t}=\delta+\alpha y_{i, t-1}+u_{i, t}
$$

One possibility, then, is to examine whether each regional GDP (or income) series independently presents a unit root, but such a procedure suffers from serious

\footnotetext{
${ }^{15}$ The values were generated using White's (1980) covariance matrix estimators.

${ }^{16}$ For early works on Chile, see Fuentes (1997); Morandé, Soto, and Pincheira (1997). Cross-sectional evidence for developed countries include convergence coefficients of $1 \%$ for the Italian regions, $1,4 \%$ for the German regions, $1,6 \%$ for the French regions, $1,7 \%$ for the American states, $1,9 \%$ for the Japanese prefectures, $2,4 \%$ for the Canadian provinces, and $3 \%$ for the British regions (see Barro and Sala-i-Martin, 1995).

${ }^{17}$ See, for example, Evans (1998); Phillips and Sul (2003); Cheung and Pascual (2004).

${ }^{18}$ We can assume in equation 2 that $T=1$ without loss of generality.
} 
power problems. ${ }^{19}$ Thus the best alternative is to undertake a panel data unit root test.

The range of panel data unit root tests has grown in recent years. We apply only the most recent to contrast the results with earlier studies and only where such tests are adaptable to the requirements of our hypothesis. We thus apply four tests: Levin, Lee, and Chu (2002); Breitung (2000); the Fisher-ADF and Fisher-Phillips-Perron tests proposed by Maddala and Wu (1999); and Choi (2001). ${ }^{20}$ Again, the null hypothesis of these tests is that there is a unit root $(\alpha=0$, without including fixed effects or trend) - that is, that there is no convergence. ${ }^{21}$ In particular, the null hipothesis for Levin-Lee-Chu and Breitung tests is $\alpha=0$ (equation 3), whereas for the Fisher-ADF and Fisher-Phillips-Perron tests, the null is $\alpha_{i}=0$ for $i=1,2, \ldots, 13$. Implicitly, the first two tests assume a common unit root process for all the regional series; in contrast, the latter tests allow the presence of individual unit root processes. To contrast the robustness of the results of these four tests, in each case we consider two information criteria for the choice of lags (Schwartz and Hannan-Quinn) and use five- and ten-year panels.

Prior to the application of the tests, we removed the temporal effects from the series, for two basic reasons. First, as mentioned earlier, we want to control for effects in the series stemming from the change in the base year, a factor that cannot be adequately addressed when undertaking unit root tests. Second, panel data unit root tests are generally constructed under the assumption of no crosssectional correlation of errors. We therefore remove the (fixed) temporal (but not idiosyncratic) effects common to the regions to avoid drastic loss of power for the autocorrelation. ${ }^{22}$

Table $1 \mathrm{~b}$ reports the modified $t$ statistics and (in parentheses) the respective $p$ values for the null hypothesis of each test. The criterion is to reject the null whenever the $p$ values are higher than standard levels of significance $(1 \%, 5 \%$, and 10\%). Thus, Table 2 shows that three of the four tests reject the unit root hypothesis of no convergence (in other words, it is not possible to discard convergence) in the case of both five- and ten-year data and using both criteria for lag selection. Here again, the empirical evidence tends to confirm the absolute convergence of per capita GDP in the regions of Chile.

\subsection{Beta Convergence in Regional Income}

Following the same empirical strategy as in the previous section, we analyze the data on regional per capital income.

\footnotetext{
${ }^{19}$ For GDP there are only 40 years (or temporal observations) and for income just 13 years (with 7 temporal observations).

${ }^{20}$ Particular features of these tests are described in Appendix A.

${ }^{21}$ These tests are designed to allow the evaluation of the absolute convergence hypothesis, in contrast with alternatives such as Im, Pesaran, and Shin (2003) or Hadri (2000), which do not allow the exclusion of fixed effects under the null hypothesis. Including fixed effects or other independent variables in the model (equation 3) would imply that we were, in fact, testing the conditional convergence hypothesis.

${ }^{22}$ This procedure is also followed by earlier authors (see Canning, 1999; Im, Pesaran, and Shin, 2003).
} 
TABLE 2

TESTS FOR $\beta$ CONVERGENCE IN GDP: PANEL UNIT ROOT TESTS ${ }^{\mathrm{a}}$

\begin{tabular}{|c|c|c|c|c|}
\hline \multirow{3}{*}{ Test } & \multicolumn{4}{|c|}{ Convergence in GDP } \\
\hline & \multicolumn{2}{|c|}{ Ten-year panel } & \multicolumn{2}{|c|}{ Five-year panel } \\
\hline & SIC & HQC & SIC & HQC \\
\hline $\begin{array}{l}\text { Levin, Liu, } \\
\text { and Chu }(2002)^{b / d}\end{array}$ & $\begin{array}{r}-2.77287 \\
(0.0028)\end{array}$ & $\begin{array}{l}-2.77287 \\
(0.0028)\end{array}$ & $\begin{array}{l}-1.94704 \\
(0.0257)\end{array}$ & $\begin{array}{r}-2.06497 \\
(0.0195)\end{array}$ \\
\hline $\begin{array}{l}\text { Breitung } \\
(2000)^{\mathrm{b}}\end{array}$ & $\begin{array}{l}0.37607 \\
(0.6466)\end{array}$ & $\begin{array}{l}0.37607 \\
(0.6466)\end{array}$ & $\begin{array}{r}-0.55321 \\
(0.2901)\end{array}$ & $\begin{array}{c}-0.57268 \\
(0.2834)\end{array}$ \\
\hline Fisher-ADF ${ }^{c}$ & $\begin{array}{l}44.1537 \\
(0.0146)\end{array}$ & $\begin{array}{l}44.1537 \\
(0.0146)\end{array}$ & $\begin{array}{l}40.5353 \\
(0.0345)\end{array}$ & $\begin{array}{l}41.1876 \\
(0.0297)\end{array}$ \\
\hline $\begin{array}{l}\text { Fisher-Phillips- } \\
\text { Perron }^{\text {c/d }}\end{array}$ & $\begin{array}{l}56.0911 \\
(0.0005)\end{array}$ & $\begin{array}{l}56.0911 \\
(0.0005)\end{array}$ & $\begin{array}{l}69.6781 \\
(0.0000)\end{array}$ & $\begin{array}{l}69.6781 \\
(0.0000)\end{array}$ \\
\hline
\end{tabular}

a. Modified $t$ statistics of each test. Series: regional GDP per capita (1960-2000). SIC denotes Schwartz information criterion; HQC denotes the Hannan-Quinn information criterion. The null hypothesis is a unit root process (no convergence). $P$ values of the null are in parentheses. See appendix A for further details.

b. Assumes a process with a common unit root.

c. Assumes a process with individual unit roots.

d. Estimations were performed using bandwidth by Andrews (1991) and the kernel quadratic spectral.

\section{Traditional Convergence Tests}

While the relationship between the growth rate from 1987 to 2000 and the initial income level (in 1987) is negative, with a coefficient close to -0.015 , it is not statistically significant at conventional levels (see Figure 4 and Table 3 ). The crosssection estimations thus do not provide clear evidence of convergence in income.

Nevertheless, the estimations using panel data, which incorporate more information (greater number of observations) since they consider the time dimension, yield evidence in favor of the hypothesis under study. Both two- and four-year estimations confirm the hypothesis of convergence, with faster rates than those found with the GDP estimates: -0.078 and -0.038 , respectively (see Table 3). ${ }^{23}$ These convergence rates imply that half the gap between poor and rich regions will close in 18 and 9 years, respectively.

\footnotetext{
${ }^{23}$ Anríquez and Fuentes (2001) find GDP convergence rates somewhat higher than $2 \%$ and income convergence rates close to $9 \%$ for the 1987-94 period. However, if we rerun the GDP regressions in table 1a for the 1987-2000 period, we still find higher convergence rates for income. Our regression results are available on request.
} 
FIGURE 4

AVERAGE GROWTH RATE AND INITIAL PER CAPITA INCOME

(Chile, 1987-2000)

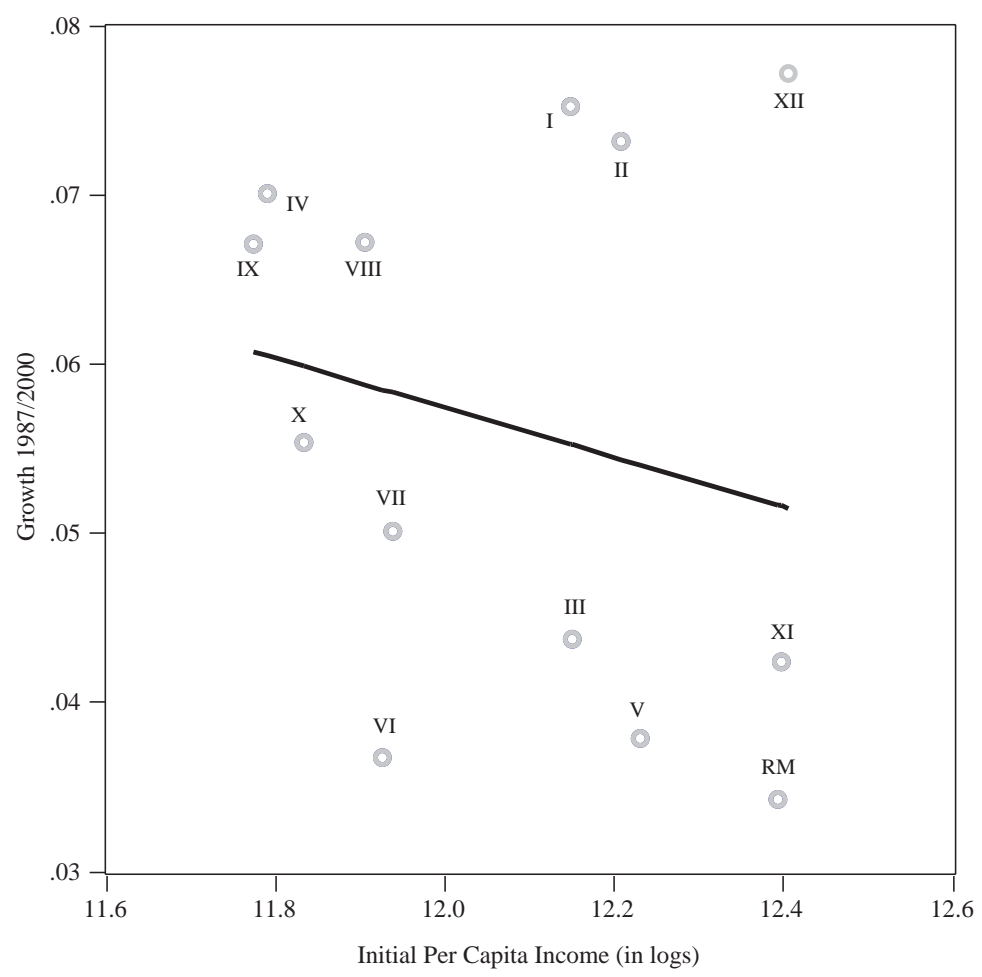

\section{Unit Root Tests}

Analogously, we apply the same set of unit root tests to per capita income series and obtain similar results to the GDP tests. For the two-year data, only the Breitung test does not support the convergence hypothesis, although its probability ( $p$ value) is not very high for the size of the sample used (15-16\%). For the fouryear data, the Breitung and Fisher-Phillips-Perron tests do not support the convergence hypothesis; in the latter case, however, the probability is only slightly higher than $10 \%$ (see Table 4). Given the low power of this type of test with small samples such as we use in this section, it is remarkable that we were able to generally reject the null hypothesis of a unit root, which confirms our previous findings. ${ }^{24}$ Thus the idea of convergence in per capita income is also valid under this approach.

${ }^{24}$ For a rough idea of the empirical power properties of the tests, see Levin, Lin, and Chu (2002, p. 17); Choi (2001, p. 260). Baltagi and Kao (2000) also discuss the power properties of some of the tests used above. 
TABLE 3

TRADITIONAL TESTS FOR $\beta$ CONVERGENCE IN INCOME: CROSS-SECTION AND POOLED PANEL DATA ${ }^{\mathrm{a}}$

\begin{tabular}{|c|c|c|c|}
\hline \multirow{2}{*}{ Coefficient } & \multicolumn{3}{|c|}{ Convergence in GDP } \\
\hline & Cross-section ${ }^{\mathrm{b}}$ & Four-year pool ${ }^{\mathrm{c}}$ & Two-year pool ${ }^{\mathrm{C}}$ \\
\hline$\beta$ & $\begin{array}{c}-0.01473 \\
(0.0198) \\
{[0.4729]}\end{array}$ & $\begin{array}{c}-0.03788 \\
(0.0143) \\
{[0.0139]}\end{array}$ & $\begin{array}{c}-0.07810 \\
(0.0330) \\
{[0.0208]}\end{array}$ \\
\hline Statistics & & & \\
\hline$R^{2}$ & 0.0472 & 0.3216 & 0.2834 \\
\hline$F$ statistic & 0.5447 & 5.5295 & 4.6803 \\
\hline$P$ value & 0.4759 & 0.0032 & 0.0005 \\
\hline No. observations & 13 & 39 & 78 \\
\hline Years to close half the gap ${ }^{d}$ & 47.1 & 18.3 & 8.9 \\
\hline
\end{tabular}

a. Series: regional per capita income (1987-2000). Standard deviations are in parentheses; $p$ values are in brackets.

b. White covariance matrix estimator was used.

c. White covariance matrix estimator was used. The panels consider growth rates every two or four years, except between the income rates of the 1987 and 1990 CASEN survey. Time effects were included; fixed or random effects were not.

d. Calculated as $\ln (1 / 2)$ divided by the respective beta coefficient.

TABLE 4

TESTS FOR $\beta$ CONVERGENCE IN INCOME: PANEL UNIT ROOT TESTS ${ }^{a}$

\begin{tabular}{lcccc}
\hline \multirow{2}{*}{ Test } & \multicolumn{4}{c}{ Convergence in GDP } \\
\cline { 2 - 5 } & \multicolumn{2}{c}{ Four-year panel } & \multicolumn{2}{c}{ Two-year panel } \\
\cline { 2 - 5 } & SIC & HQC & SIC & HQC \\
\hline Levin, Liu, and $_{\text {Chu (2002) }}^{\text {b/d }}$ & -2.43374 & -2.43374 & -2.15993 & -2.17693 \\
Breitung $_{(2000)^{\mathrm{b}}}$ & $(0.0075)$ & $(0.0075)$ & $(0.0154)$ & $(0.0147)$ \\
Fisher-ADF $^{c}$ & 0.37188 & 0.37188 & -0.97247 & -1.02172 \\
& $(0.6450)$ & $(0.6450)$ & $(0.1654)$ & $(0.1535)$ \\
Fisher-Phillips $_{\text {-Perron }^{\text {c/d }}}$ & 35.1434 & 35.1434 & 39.1113 & 38.9737 \\
\hline
\end{tabular}

a. Modified $t$ statistics of each test. Series: regional per capita income (1987-2000). SIC denotes Schwartz information criterion; HQC denotes the Hannan-Quinn information criterion. The null hypothesis is a unit root process (no convergence). $P$ values of the null are in parentheses. See appendix A for further details.

b. Assumes a process with a common unit root.

c. Assumes a process with individual unit roots.

d. Estimations were performed using bandwidth by Andrews (1991) and the kernel quadratic spectral. 


\subsection{Conditional $\beta$ Convergence}

To complete the sensitivity analysis, we performed conditional $\beta$ convergence tests. We carried out tests similar to those described above for the 1960-2000 period, whenever feasible incorporating explanatory variables that allow us to approximate the potentially distinct steady states of each region. In this case we were able to carry out panel data tests. ${ }^{25}$ Here, however, we incorporated fixed effects for each region and other explanatory variables (such as mining and education) to capture idiosyncratic effects that could be affecting the convergence of the regions. ${ }^{26}$

The results support the existence of conditional convergence of GDP (see Table 3). The importance of mining on the regional productive structure was the only statitiscally significant variable in the conditional convergence regression. ${ }^{27}$ Years of education of the labor force and the share of other sectors on total GDP were not statistically significant for explaining growth. This means that regions that are abundant in mineral resources will converge to a different steady state from the rest. For the ten-year GDP panel, we found a coefficient of -0.014 , which implies that half the gap will close in 72 years (see Table 5, column 1). This result contrasts with the one in table 1a, where for the ten-year pooling regression coefficient was -0.0074 and half the gap will close in 94 years. At this point, it is important to notice that the convergence hypothesis relies on the idea that all the economies have the same production function. If natural resources are important for one region, then the aggregate production function and the final steady state will be different for that region.

In sum, the empirical evidence generally backs up the hypothesis of $\beta$ convergence for both per capita income and GDP, showing higher convergence rates in the conditional case. The increase of the beta coefficients from absolute to conditional convergence tests is also observed in most of the regional evidence for developed countries. Barro and Sala-i-Martin (1995) found coefficients of $1.6 \%$ for Italy, $1.6 \%$ for Germany, $2.2 \%$ for the United States, and 3.1\% for Japan. Although the coefficients are not strictly comparable, the average difference between the cross-section and panel coefficient values for theses studies is around 0.63 percentage points, closely similar to our findings (about 0.68 percentage points). This fact might reveal the omission of relevant variables -in our case, mining- in the absolute convergence regressions, since those variables may capture differences in the region's steady states. Statistically speaking, the sign of the bias due to relevant variable omission is governed by the correlation between the regressors (the lag of per capita GDP) and the omitted variable (mining). In our case, only a negative correlation between mining and the lag of GDP can

\footnotetext{
${ }^{25}$ Because it is not feasible to carry out unit root tests including other dependent variables that are not trends or fixed effects.

${ }^{26}$ Mining is measured as the mining sector's share of output in region $i$ over total GDP in region $i$. Education is measured as the average years of schooling of the labor force in each region.

${ }^{27}$ This is consistent with the findings in Fuentes (1997).
} 
TABLE 5

TESTS OF CONDITIONAL CONVERGENCE IN GDPa

\begin{tabular}{|c|c|c|c|c|c|c|c|}
\hline \multirow{3}{*}{ Coefficient } & \multicolumn{7}{|c|}{ Conditional convergence in GDP: Ten-year panel ${ }^{\mathrm{b}}$} \\
\hline & \multicolumn{3}{|c|}{ Without fixed effects } & \multicolumn{4}{|c|}{ With fixed effects } \\
\hline & (1) & (2) & (3) & (4) & (5) & (6) & (7) \\
\hline$\beta$ & $\begin{array}{c}-0.01406 \\
{[0.0045]}\end{array}$ & $\begin{array}{c}-0.00962 \\
{[0.0353]}\end{array}$ & $\begin{array}{c}-0.01878 \\
{[0.0045]}\end{array}$ & $\begin{array}{r}-0.04187 \\
{[0.0224]}\end{array}$ & $\begin{array}{r}-0.05248 \\
{[0.0038]}\end{array}$ & $\begin{array}{r}-0.04256 \\
{[0.0395]}\end{array}$ & $\begin{array}{r}-0.05067 \\
{[0.0074]}\end{array}$ \\
\hline Mining $^{c}$ & $\begin{array}{l}0.03026 \\
{[0.0647]}\end{array}$ & $\ldots$ & $\begin{array}{c}0.0335 \\
{[0.0416]}\end{array}$ & $\begin{array}{l}\ldots \\
\ldots\end{array}$ & $\begin{array}{l}0.06571 \\
{[0.1270]}\end{array}$ & $\begin{array}{l}\ldots \\
\ldots\end{array}$ & $\begin{array}{l}0.07169 \\
{[0.1052]}\end{array}$ \\
\hline Education $^{\mathrm{d}}$ & $\begin{array}{l}\ldots \\
\ldots\end{array}$ & $\begin{array}{c}0.0024 \\
{[0.4027]}\end{array}$ & $\begin{array}{l}0.00383 \\
{[0.2118]}\end{array}$ & $\begin{array}{l}\ldots \\
\ldots\end{array}$ & $\begin{array}{l}\ldots \\
\ldots\end{array}$ & $\begin{array}{l}0.00072 \\
{[0.8984]}\end{array}$ & $\begin{array}{l}-0.00288 \\
{[0.6112]}\end{array}$ \\
\hline Statistics & & & & & & & \\
\hline$R^{2}$ & 0.6022 & 0.5653 & 0.6151 & 0.7145 & 0.7373 & 0.7146 & 0.7390 \\
\hline$F$ statistic & 11.35 & 9.75 & 10.04 & 5.01 & 5.15 & 4.59 & 4.77 \\
\hline$P$ value & 0.00000 & 0.00000 & 0.00000 & 0.00003 & 0.00002 & 0.00007 & 0.00005 \\
\hline $\begin{array}{l}\text { Years to close } \\
\text { half the gap }\end{array}$ & 72.0 & 72.1 & 36.9 & 16.6 & 13.2 & 16.3 & 13.7 \\
\hline
\end{tabular}

a. Series: Regional GDP per capita (1960-2000). Number of observations: 52.

b. $P$ values are in brackets. White covariance matrix estimator was used. Time effects were included. Fixed effects were included as indicated above.

c. Share of mining GDP of region $i$ in the region's total GDP.

d. Average years of schooling of the work force.

e. Calculated as $\ln (1 / 2)$ divided by the respective beta coefficient.

explain the underestimation of the beta coefficient value. Empirically, regions with lower initial levels of per capita GDP present a higher share of mining on the regional productive structure in the transition to the steady-state equilibrium.

\subsection{Sigma Convergence of Regional GDP}

As described earlier, another relevant type of convergence is $\sigma$ convergence. We have shown that, in general, the evidence clearly supports $\beta$ convergence in GDP and income, which is a necessary but not sufficient requirement for the existence of $\sigma$ convergence. We must now analyze the behavior of the dispersion of the indicators of output and income across time.

A first piece of evidence of $\sigma$ convergence in GDP can be seen in figure 1 . A quick look suggests that in 2000 (the last available year), the regions presented a lower dispersion of the per capita GDP series than in 1960. Moreover, as can be seen in Table 6 , the difference between minimum and maximum per capita output has lowered in recent years, in contrast with the 1970s. 
TABLE 6

SIGMA CONVERGENCE IN GDP: MEASURES OF DISPERSION AND DESCRIPTIVE STATISTICS ${ }^{a}$

\begin{tabular}{lcccccccc}
\hline Statistics & 1965 & 1970 & 1975 & 1980 & 1985 & 1990 & 1995 & 2000 \\
\hline Mean & 5.3183 & 5.3743 & 5.2897 & 5.4991 & 5.4845 & 5.6719 & 5.9438 & 6.1084 \\
Median & 5.2865 & 5.4730 & 5.3232 & 5.5021 & 5.4513 & 5.6350 & 5.8908 & 5.9511 \\
Maximum & 6.6788 & 6.5003 & 6.2444 & 6.6144 & 6.6091 & 6.7150 & 6.7719 & 7.1106 \\
Minimum & 4.3215 & 4.3991 & 4.4247 & 4.5870 & 4.5920 & 4.8389 & 5.1517 & 5.2733 \\
Max. - Min. & 2.3573 & 2.1013 & 1.8197 & 2.0273 & 2.0171 & 1.8761 & 1.6201 & 1.8373 \\
Standard deviation & 0.6221 & 0.5671 & 0.4986 & 0.5781 & 0.5559 & 0.5166 & 0.4835 & 0.5002 \\
Skewness & 0.4408 & 0.1377 & 0.1957 & 0.3845 & 0.5179 & 0.6116 & 0.2796 & 0.4478 \\
Kurtosis $_{\text {Jarque-Bera }}^{\mathrm{b}}$ & 2.9700 & 2.6406 & 2.6732 & 2.5602 & 2.8251 & 2.9336 & 2.2064 & 2.6311 \\
Probability $^{\mathrm{b}}$ & 0.4214 & 0.1111 & 0.1408 & 0.4250 & 0.5977 & 0.8129 & 0.5105 & 0.5083 \\
\hline
\end{tabular}

Source: Central Bank of Chile: authors' calculations.

a. Series: Log of regional per capita GDP (five-year periods, 1965-2000).

b. The null hypothesis is the normality of the series.

A way to verify $\sigma$ convergence commonly used in the literature consists of constructing the variance of the log of regional GDP and observing its evolution over time. As explained in section 2, if the variance decreases in the period of analysis, then there is evidence in favor of $\sigma$-type convergence ${ }^{28}$.

While the variance of regional GDP shows clear fluctuations, it generally follows a decreasing trajectory (see Figure 5). To test this claim, we construct a $90 \%$ confidence interval for the sample variance estimator, in contrast to earlier studies. In spite of a drastic decrease from 0.37 (1960) to 0.25 (2000), the confidence intervals do not allow us to affirm categorically that the reduction was stistically significant at $10 \%$, since the final value of the variance in 2000 falls within the initial confidence interval constructed for $1960 .^{29}$

Another way to analyze the dispersion of regional GDP is by estimating its empirical distributions in each year and observing its behavior over time. ${ }^{30}$ This is carried out through (nonparametric) kernel density estimations of the series distribution. The simplest estimate of a density function is a histogram. Briefly, the weighted kernel function determines the way the bars of the histogram

\footnotetext{
${ }^{28}$ If $\beta$ is less than zero, the variance will converge to its steady-state level. This implies that the variance could increase or decrease over time depending on whether its initial value is below or above the corresponding steady-state value.

${ }^{29}$ Since we verified that the regional GDP is normally distributed (see Jarque-Bera tests in Table 6), we used an asymptotic confidence interval for the sample variance estimator using the corresponding chi-squared distribution.

${ }^{30}$ See, for example, Quah (1996c, 1997).
} 
FIGURE 5

SIGMA CONVERGENCE: VARIANCE OF PER CAPITA GDP AND CONFIDENCE INTERVAL AT 90\% (1960-2000)

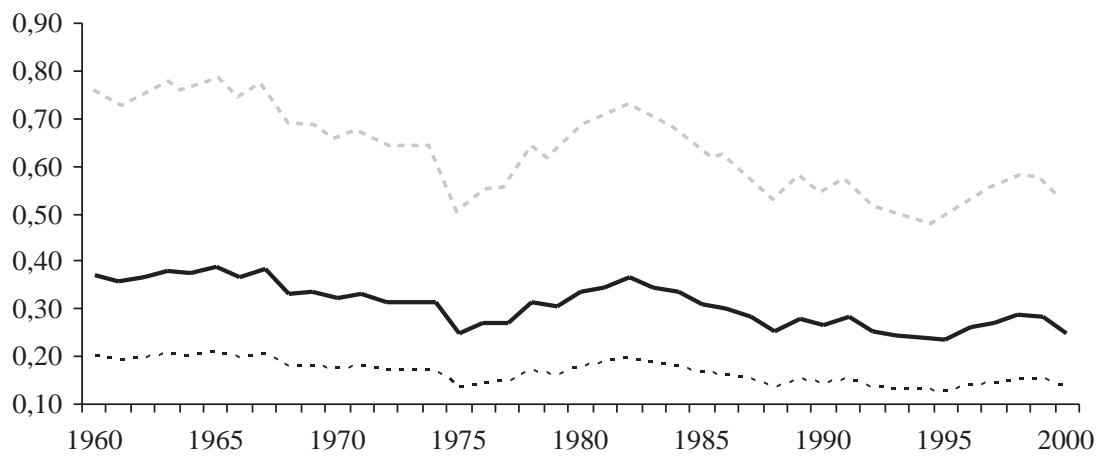

Source: Central Bank of Chile. Authors' elaboration.

smooth out and become continuous, allowing the analyst to observe a density distribution of the data. ${ }^{31}$

Figure 6 shows the distribution of regional GDP every five years since 1965 (end-of-period data). As shown in the figure, 1965 starts with a partially unimodal distribution that is highly volatile; this pattern is maintained until 1980 (see Table 6). From that year until 1990 -basically the period in which economic reforms were applied in Chile- we note the appearance of a bimodal distribution or "club", as it is known in the growth literature. ${ }^{32}$ In other words, this period seems to display a transitory convergence among groups of regions, but not among all of the regions as a whole. This feature disappears in the 1990s (see Figure 6).

To confirm this phenomenon, we carried out nonparametric multimodality tests (see Bianchi, 1997) on the per capita GDP series to determine whether the apparent asymmetries are statistically significant. ${ }^{33}$ We also considered the series expressed relative to the country's total GDP to check the robustness of our findings.

Under the null hypothesis, the empirical distribution of the series has $m$ modes. The alternative hypothesis is that the distribution has more than $m$ modes. The strategy we follow involves testing first the null hypothesis of $m=1$ mode. If this is not rejected, then the evaluation of multimodality is finished. If, on the other hand, the null hypothesis is rejected, then we proceed to evaluate a new null hypothesis of $m+1$ modes, and so on until the new hypothesis is not rejected. We reject the null hypothesis whenever the respective $p$ value is smaller than the standard levels of significance.

\footnotetext{
${ }^{31}$ We used normal approximations since the Jarque-Bera test yields a high probability in favor of it, as mentioned above, although the results do not change appreciably with other distributions. We used the smoothing parameter (h) as the base case, following Silverman's (1986) method.

${ }^{32}$ See, for example, Baumol (1986); Quah (1996a, 1996b, 1996c).

${ }^{33}$ Appendix B contains a brief description of the test and the empirical strategy followed.
} 
FIGURE 6

TEST FOR $\sigma$ CONVERGENCE IN GDP: KERNEL DENSITIES OF REGIONAL PER CAPITA GDP

Kernel density of regional GDP, 1965 (normal distribution, $\mathrm{h}=0.3221$ )

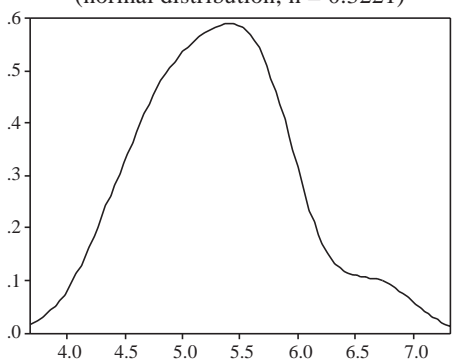

Kernel density of regional GDP, 1975 (normal distribution, $\mathrm{h}=0.1910$ )

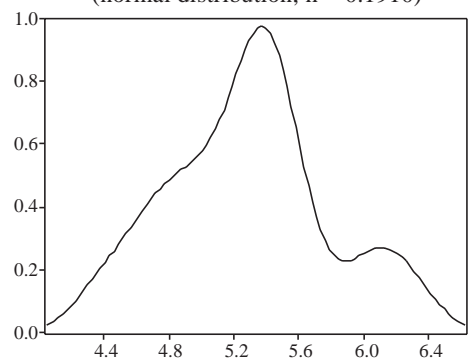

Kernel density of regional GDP, 1985 (normal distribution, $\mathrm{h}=0.1916$ )

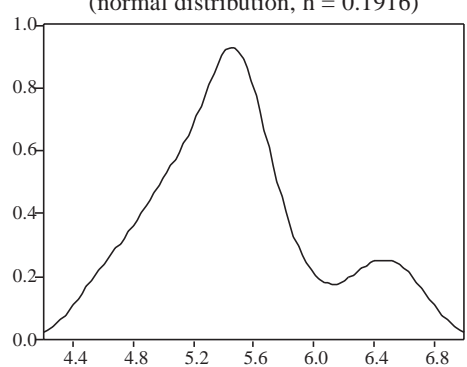

Kernel density of regional GDP, 1995 (normal distribution, $\mathrm{h}=0.2222$ )

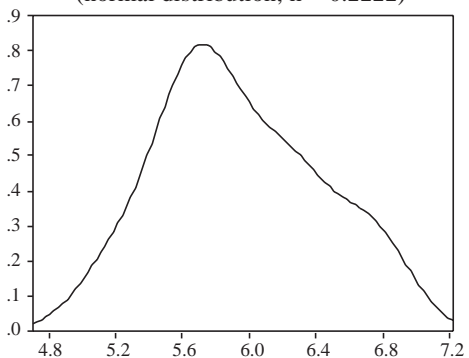

Kernel density of regional GDP, 1970 (normal distribution, $\mathrm{h}=0.2755$ )

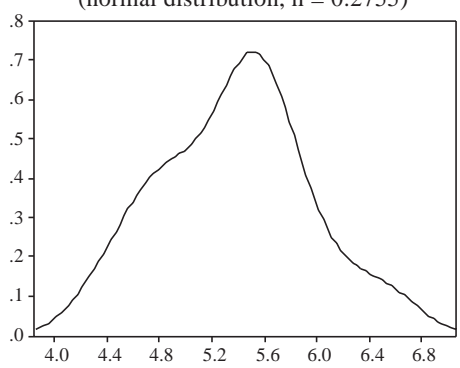

Kernel density of regional GDP, 1980 (normal distribution, $\mathrm{h}=0.2125$ )

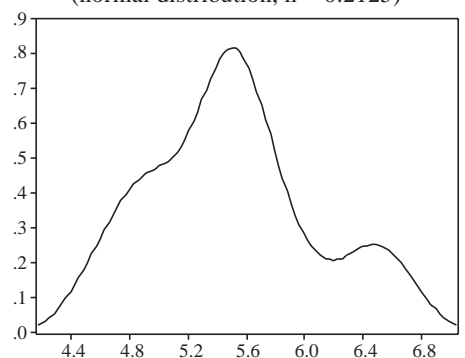

Kernel density of regional GDP, 1990 (normal distribution, $\mathrm{h}=0.1621$ )

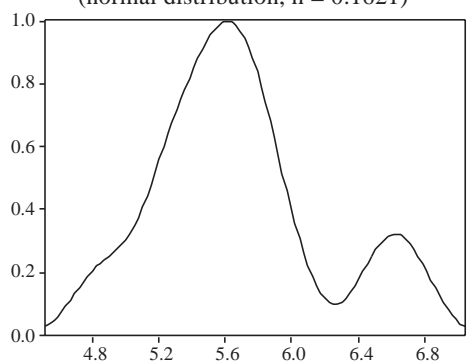

Kernel density of regional GDP, 2000 (normal distribution, $\mathrm{h}=0.2035$ )

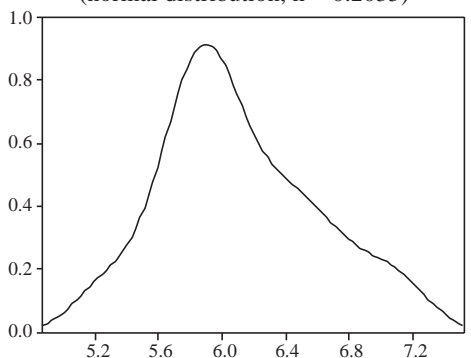


Table 7 presents the results of this test (values of the statistics and $p$ values, respectively). In the case of the series expressed in logs -which is the main series under study- the test concludes that we cannot reject the null hypothesis of unimodality at conventional levels of significance and for the whole period of the analysis (for all the years, the $p$ values are higher than 10\%). The results are similar for the cases of GDP in relative terms, with the exception of the years 1960 and 1965 (only at a 10\% level of significance). That is, there generally is not statistical evidence in favor of the formation of convergence clubs in Chile.

TABLE 7

SIGMA CONVERGENCE IN GDP: MULTIMODALITY TEST ${ }^{\mathrm{a}}$

\begin{tabular}{lcccc}
\hline & \multicolumn{2}{c}{ Statistic $^{\mathrm{b}}$} & \multicolumn{2}{c}{$P$ value $^{\mathrm{b}}$} \\
\hline Log of per capita & $H_{0}: m=1$ & $H_{0}: m=2$ & $H_{0}: m=1$ & $H_{0}: m=2$ \\
\hline 1960 & 0.320 & $\ldots$ & 0.352 & $\ldots$ \\
1965 & 0.312 & $\ldots$ & 0.417 & $\ldots$ \\
1970 & 0.237 & $\ldots$ & 0.629 & $\ldots$ \\
1975 & 0.225 & $\ldots$ & 0.521 & $\ldots$ \\
1980 & 0.265 & $\ldots$ & 0.509 & $\ldots$ \\
1985 & 0.274 & $\ldots$ & 0.429 & $\ldots$ \\
1990 & 0.287 & $\ldots$ & 0.274 & $\ldots$ \\
1995 & 0.189 & $\ldots$ & 0.746 & $\ldots$ \\
2000 & 0.153 & $\ldots$ & 0.927 & $\ldots$ \\
\hline Relative per capita GDP & & & & \\
1960 & 0.047 & 0.017 & 0.052 & 0.158 \\
1965 & 0.046 & 0.015 & 0.061 & 0.280 \\
1970 & 0.030 & $\ldots$ & 0.167 & $\ldots$ \\
1975 & 0.022 & $\ldots$ & 0.353 & $\ldots$ \\
1980 & 0.027 & $\ldots$ & 0.314 & $\ldots$ \\
1985 & 0.026 & $\ldots$ & 0.369 & $\ldots$ \\
1990 & 0.030 & $\ldots$ & 0.140 & $\ldots$ \\
1995 & 0.021 & $\ldots$ & 0.306 & $\ldots$ \\
\hline
\end{tabular}

a. Multimodality test (with bootstrapping, 1,000 simulations). The modes correspond to the empirical distribution of the per capita GDP series expressed in logs of levels and in relative terms to the country's total per capita GDP.

b. Statistic and probability under $\mathrm{H}_{0}$ : the density function of the series has $m$ modes; under $\mathrm{H}_{1}$ : the density function has more than $m$ modes. The statistic corresponds to the estimated critical bandwidth. See appendix B for further details. 


\subsection{Sigma Convergence in Regional Income}

Contrary to what we found in the case of GDP, $\sigma$ convergence does not appear to have changed greatly at the level of regional income in the 1987-2000 period. As shown in Figure 7, the variance of regional incomes has generally increased, although not significantly, despite having been reduced in the early 1990s. The evolution of other statistics, such as the difference between the maximum and minimum values, also points in this direction (see Table 8 ). When we look at the $90 \%$ confidence interval, however, the value of the variance toward the end of the period (in 2000) is not statistically different from the initial value (in 1987). This implies that while there is no $\sigma$ convergence in the period, neither is there a process of divergence that would contradict our results for regional GDP $^{34}$ It is very important to emphasize that this behavior is extremely similar to that shown by the variance of regional GDP for the same period (see Figure 5 ), which indicates consistency in the results. On the other hand, recall that the sources to construct our regional income series are of limited quality, so this fact might also be affecting our findings.

\section{FIGURE 7}

SIGMA CONVERGENCE: VARIANCE OF PER CAPITA INCOME AND CONFIDENCE INTERVAL AT 90\% (1987-2000)

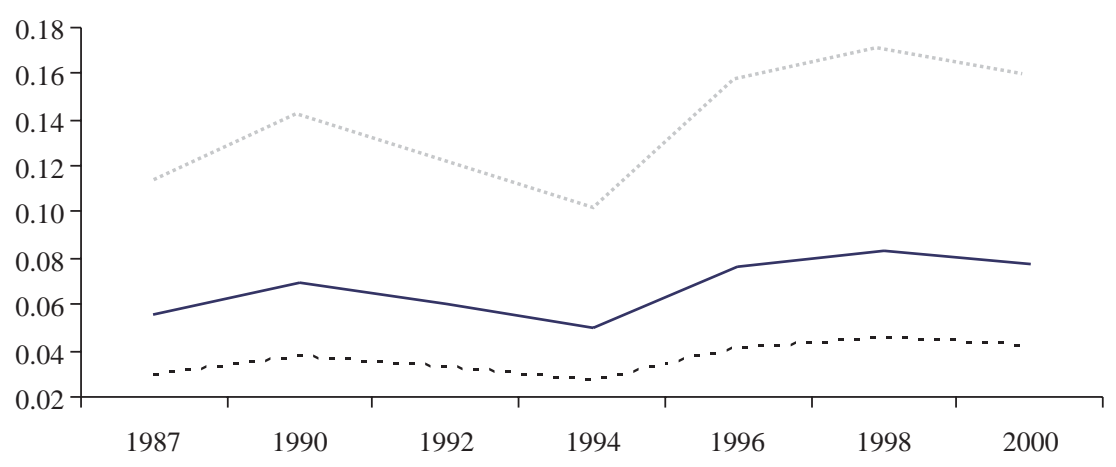

Source: CASEN. Authors' elaboration.

When we calculate the empirical distributions through the kernel estimator, we also observe the appearance of supposed regional clubs in bimodal distributions and with high dispersion, especially in the years 1987, 1992, and 1998 (see Figure 8). However, they tend to disappear in 2000.

The application of the multimodality test also reveals that the apparent bimodality of the regional income distribution is not, in fact, statistically significant (see Table 9). Under the null hypothesis of unimodality, the values of

\footnotetext{
${ }^{34}$ Alternative explanations for the case of economic agglomeration and growth can be found in Fujita and Thisse (2002).
} 
TABLE 8

SIGMA CONVERGENCE IN INCOME: MEASURES OF DISPERSION AND DESCRIPTIVE STATISTICS ${ }^{a}$

\begin{tabular}{lrrrrrrr}
\hline Statistic & 1987 & 1990 & 1992 & 1994 & 1996 & 1998 & 2000 \\
\hline Mean & 12.0847 & 12.2108 & 12.2764 & 12.3740 & 12.4505 & 12.5280 & 12.8141 \\
Median & 12.1480 & 12.2567 & 12.3363 & 12.3579 & 12.4553 & 12.4742 & 12.7233 \\
Maximum & 12.4064 & 12.7586 & 12.7415 & 12.8250 & 12.9600 & 13.0072 & 13.4103 \\
Minimum & 11.7734 & 11.7101 & 11.9491 & 12.0256 & 11.9963 & 12.1101 & 12.4049 \\
Max. - Min. & 0.6330 & 1.0485 & 0.7924 & 0.7995 & 0.9637 & 0.8970 & 1.0054 \\
Standard deviation & 0.2356 & 0.2641 & 0.2467 & 0.2226 & 0.2771 & 0.2893 & 0.2782 \\
Skewness & 0.0943 & 0.1448 & 0.2190 & 0.3459 & 0.0418 & 0.5439 & 0.7114 \\
Kurtosis $_{\text {Jarque-Bera }}^{\text {b }}$ & 1.5512 & 3.0781 & 1.9834 & 2.5026 & 2.2983 & 2.1890 & 2.7931 \\
Probability $^{\mathrm{b}}$ & 1.1562 & 0.0487 & 0.6638 & 0.3932 & 0.2705 & 0.9973 & 1.1196 \\
& 0.5610 & 0.9759 & 0.7176 & 0.8215 & 0.8735 & 0.6074 & 0.5713 \\
\hline
\end{tabular}

Source: CASEN; authors' calculations.

a. Series: Log of regional per capita income (1987-2000).

b. The null hypothesis is the normality of the series.

TABLE 9

SIGMA CONVERGENCE IN INCOME: MULTIMODALITY TEST ${ }^{\mathrm{a}}$

\begin{tabular}{|c|c|c|c|c|}
\hline \multirow[b]{2}{*}{ Log of per capita income } & \multicolumn{2}{|c|}{ Statistic ${ }^{\mathrm{b}}$} & \multicolumn{2}{|c|}{$P$ value ${ }^{\mathrm{b}}$} \\
\hline & $H_{0}: m=1$ & $H_{0}: m=2$ & $H_{0}: m=1$ & $H_{0}: m=2$ \\
\hline 1987 & 0.16056 & 0.09120 & 0.09500 & 0.10000 \\
\hline 1990 & 0.12038 & $\ldots$ & 0.53300 & $\ldots$ \\
\hline 1992 & 0.15888 & $\ldots$ & 0.11700 & $\ldots$ \\
\hline 1994 & 0.09294 & $\ldots$ & 0.66300 & $\ldots$ \\
\hline 1996 & 0.08739 & $\ldots$ & 0.91200 & $\ldots$ \\
\hline 1998 & 0.17457 & $\ldots$ & 0.19000 & $\ldots$ \\
\hline 2000 & 0.11029 & $\ldots$ & 0.72700 & $\ldots$ \\
\hline \multicolumn{5}{|l|}{ Relative per capita income } \\
\hline 1987 & 0.00911 & $\ldots$ & 0.46500 & $\ldots$ \\
\hline 1990 & 0.01302 & $\ldots$ & 0.18800 & $\ldots$ \\
\hline 1992 & 0.01171 & $\ldots$ & 0.17600 & $\ldots$ \\
\hline 1994 & 0.00901 & $\ldots$ & 0.40900 & $\ldots$ \\
\hline 1996 & 0.00937 & $\ldots$ & 0.57800 & $\ldots$ \\
\hline 1998 & 0.01596 & $\ldots$ & 0.12000 & $\ldots$ \\
\hline 2000 & 0.01214 & $\ldots$ & 0.45300 & $\ldots$ \\
\hline
\end{tabular}

a. Multimodality test (with bootstrapping, 1000 simulations). The modes correspond to the empirical distribution of the per capita income series expressed in logs of levels and in relative terms to the country's total per capita income.

b. Statistic and probability under $\mathrm{H}_{0}$ : the density function of the series has $m$ modes; under $\mathrm{H}_{1}$ : the density function has more than $m$ modes. The statistic corresponds to the estimated critical bandwidth. See appendix B for further details. 
FIGURE 8

\section{TEST FOR $\sigma$ CONVERGENCE IN INCOME: KERNEL DENSITIES OF REGIONAL PER CAPITA INCOME}

Kernel density of regional income, 1987

(normal distribution, $\mathrm{h}=0.1220$ )

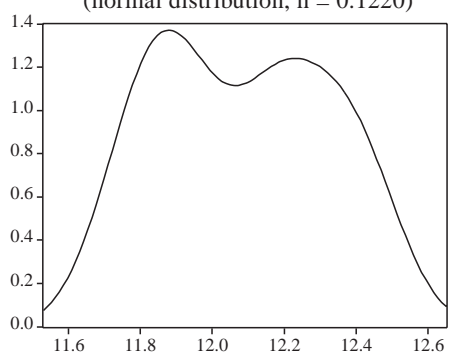

Kernel density of regional income, 1992 (normal distribution, $\mathrm{h}=0.1272$ )

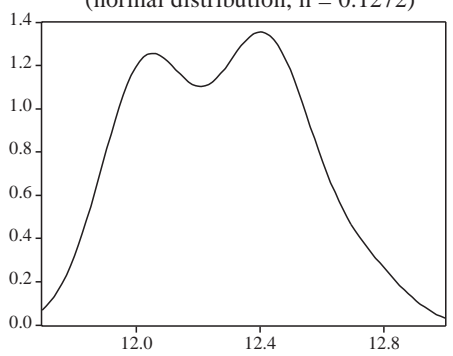

Kernel density of regional income, 1996 (normal distribution, $\mathrm{h}=0.1435$ )

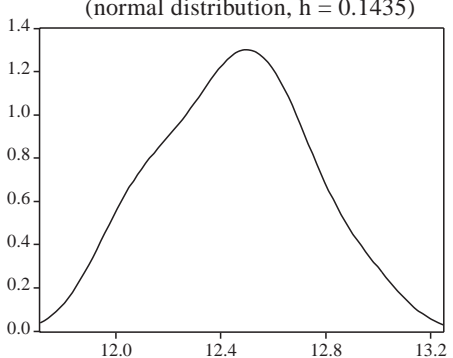

Kernel density of regional income, 1990 (normal distribution, $\mathrm{h}=0.1074$ )

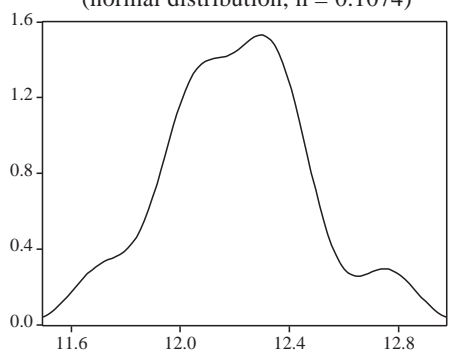

Kernel density of regional income, 1994 (normal distribution, $\mathrm{h}=0.1074$ )

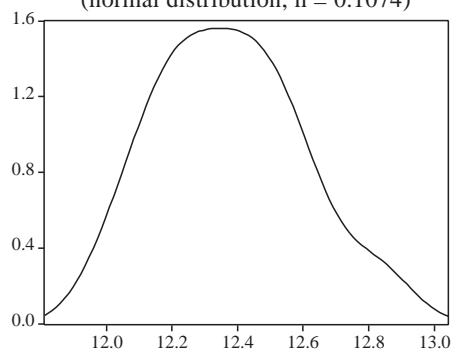

Kernel density of regional income, 1998 (normal distribution, $\mathrm{h}=0.0863$ )

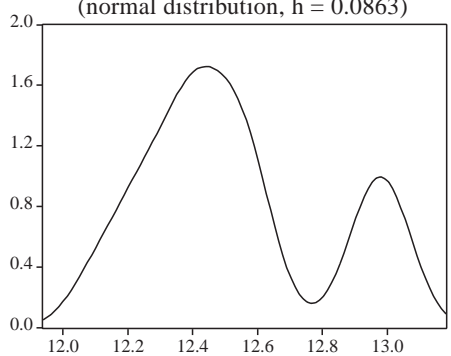

Kernel density of regional income, 2000 (normal distribution, $\mathrm{h}=0.0940$ )

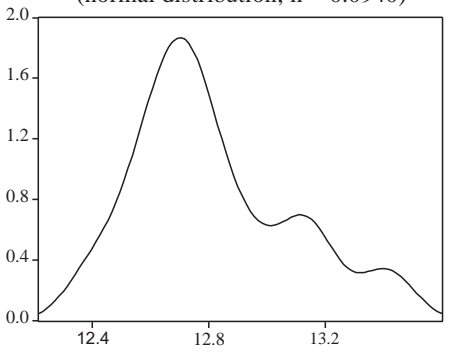


the statistics and probabilities are such that they allow us to reject the idea of multimodality in the estimated density of the series between 1990 and 2000, at standard levels of significance. In the case of the series expressed in relative terms, it is not possible to reject the unimodality of the series from 1987 on, which is consistent with the results of the same test applied to the GDP series.

\section{Conclusions}

The empirical evidence for the 1960-2000 period in Chile tends to support the hypothesis of convergence in regional GDP per capita, for both $\beta$-type convergence (convergence in levels) and $\sigma$-type convergence (convergence in dispersion).

The unit root tests employed mostly reject the presence of stochastic trend processes in favor of deterministic trend processes (trend stationary processes). That is, the evidence is strongly consistent with the neoclassical growth theory and the presence of convergence in both the regional per capita GDP and income series.

However, this result -which we also found through traditional panel and cross-section convergence tests- is accompanied by slow rates of convergence (relative to the international evidence) of slightly under $1 \%$. This implies that the period for closing half the gap between relatively poor and rich regions ranges from 81 to 96 years.

Our analysis of conditional convergence finds that the speed increases to a range of $1.4 \%$ to $5.2 \%$ (with half the gap closing in a period of between 72 and 13 years, respectively) when we control for the share of the mining sector. This appears to be consistent with the idea that the regions are converging to their own steady state. Variables like average education of the work force do not appear to be good approximations for characterizing the steady states because they are not statistically significant.

The analysis of $\sigma$ convergence or convergence of the variance of regional per capita GDP shows that the variance has undergone a (statistically nonsignificant) decrease for the full period. Nevertheless, this drop has not been constant and has included periods in which the estimator increased notably. The volatility of this indicator coincides with the period between the 1975 and 1982 crises, and the recent international turbulence starting with the Asian crisis. ${ }^{35}$ On the other hand, while the empirical distributions of per capita GDP initially show bimodalities or possible convergence clubs, these are largely rejected through multimodality tests.

With regard to per capita income, the results on convergence are relatively favorable for $\beta$ convergence, but we do not observe a statistically significant reduction in its dispersion. Given the short span of our income sample, this behavior is extremely similar to that shown by the variance of regional GDP for the same period, which indicates consistency in the findings. Moreover, the application of the multimodality test reveals that the apparent asymmetries or bimodalities of the regional income distribution are not, in fact, statistically significant.

\footnotetext{
${ }^{35}$ This does not necessarily imply causality.
} 


\section{APPENDIX A \\ UNIT ROOT TESTS ${ }^{36}$}

Levin, Lin, and Chu (2002)

This test assumes that there is a common unit root process in the series. It considers the standard specification of an augmented Dickey-Fuller (ADF) test, but applied to panel data:

(A1) $\Delta y_{i, t}=\alpha y_{i, t-1}+\sum_{j=1}^{p} \lambda_{i j} \Delta y_{i, t-j}+\delta \mathbf{X}+v_{i, t}$,

where $\mathrm{a}=\beta-1$ is a common coefficient to the series, but different orders of lags $\left(p_{i}\right)$ of $\Delta y_{i \mathrm{t}}$ are allowed in the cross-section; and $\mathbf{X}$ is a vector of deterministic variables (for example, seasonal or trend dummies). The hypothesis to evaluate is

$\mathrm{H}_{0}: \alpha=0$, against

$\mathrm{H}_{1}: \alpha<0$ (that the series are weakly stationary or trend stationary).

In general terms, the test follows four stages.

(i) Estimate the ADF regressions (as in equation A1) for each region; find the optimal number of lags $\left(p_{\mathrm{i}}\right)$ using $t$ tests; and estimate two auxiliary regressions to generate orthogonal residuals. The residuals are generated by regressing $\Delta y_{i, t}$ and $y_{i, t-1}$ against $y_{i, t-L}$ (where $L=1, \ldots, p_{i}$ ) and the relevant deterministic variables (X). The idea here is to generate approximations of the variables $\Delta y_{i, t}$ and $y_{i, t-1}$ that are free from autocorrelation, an assumption on which the test is built.

(ii) Collect the residuals from the regressions and normalize them by dividing by the standard error of regression A1 (denote them as $\Delta y^{*}$ and $y^{*}$ ).

(iii) Use the approximations to obtain estimators of a in the following specification:

$$
\text { (A2) } \Delta y_{i, t}^{*}=\alpha y_{i, t-1}^{*}+u_{i, t} \text {. }
$$

(iv) Finally, construct a modified $t$ statistic that will be asymptotically standard normal distributed and compare with the pertinent critical values. That is, construct:

$$
t_{\alpha}=\frac{\hat{\alpha}}{s t d(\hat{\alpha})}
$$

where

\footnotetext{
${ }^{36}$ For further detail on the tests described in this appendix, please see the original works cited.
} 


$$
\begin{aligned}
& \operatorname{std}(\hat{\alpha})=\hat{\sigma}_{\tilde{e}}\left[\sum_{i=1}^{N} \sum_{t=2+p_{i}}^{T}\left(y_{i, t-1}^{*}\right)^{2}\right]^{-1 / 2}, \text { and } \\
& \hat{\sigma}_{\tilde{e}}=\left[\frac{1}{N(T-\bar{p}-1)} \sum_{i=1}^{N} \sum_{t=2+p_{i}}^{T}\left(\Delta y_{i, t}^{*}-\hat{\alpha} y_{i, t-1}^{*}\right)^{2}\right], \text { con } \bar{p}=\left(\frac{1}{N}\right) \sum_{i=1}^{N} p_{i} \text {, and where }
\end{aligned}
$$

$\hat{\alpha}$ is the estimator of expression A2.

\section{Breitung (2000)}

This test assumes the presence of a single nonstationary process in the series and constructs a modified $t$ statistic that is asymptotically standard normal distributed. It differs from the previous one in two basic aspects. First, in stage (i), remove only the autoregressive component (and not the deterministic component). Second, the (new) approximations are transformed and their trends extracted. The remaining features and the null hypothesis are the same as in the Levin, Lin, and Chu (2002) test.

\section{Fisher-ADF and Fisher-Phillips-Perron}

These tests were proposed by Maddala and Wu (1999) and Choi (2001). In contrast with the previous tests, these allow the presence of individual unit root processes. That is, regression A1 is run for each series, but now we evaluate

$\mathrm{H}_{0}: \alpha_{\mathrm{i}}=0, \forall i$ all the series have a unit root, that is, all the coefficients of persistence are the same and equal to zero); against

$\mathrm{H}_{1}: \alpha_{\mathrm{i}}=0, \forall i=1,2, \ldots, \mathrm{N}_{1} ; \alpha_{\mathrm{i}}<0, \forall i=\mathrm{N}+1, \mathrm{~N}+2, \ldots, \mathrm{N}$ (a fraction of the total series is stationary).

In particular, the Fisher-ADF and Fisher-Phillips-Perron tests use the $p$ values $\left(\pi_{\mathrm{i}}\right)$ of the augmented Dickey-Fuller and Phillips-Perron tests, respectively, applied to each series in order to construct a test that under the null hypothesis is asymptotically chi-squared distributed with $2 N$ degrees of freedom (where $N$, in our case, is the number of regions):

$$
-2 \sum_{i=1}^{N} \log \left(\pi_{i}\right) \rightarrow \chi_{2 N}^{2}
$$

Furthermore, Choi (2001) showed that

$$
\frac{\sum_{i=1}^{N} \Phi^{-1}\left(\pi_{i}\right)}{\sqrt{N}} \rightarrow N(0,1)
$$


where $\Phi^{-1}$ is the inverse of the cumulative distribution function of a standard normal.

In all cases it is necessary to specify the number of lags used in the test. In the cases of Levin, Lin, and Chu (2002) and Fisher-Phillips-Perron, it is also necessary to specify the kernel method and the bandwidth selection for the zerofrequency spectral estimation.

\section{APPENDIX B MULTIMODALITY TEST}

We use the nonparametric multimodality test proposed by Bianchi (1997). The contrast is based on the estimation of the data density function using kernel methods and on testing the number of groups ("clubs" for the case of economic convergence) within a single distribution using the bootstrap technique.

The key concept in the estimation of the density function $(f(x))$ is the critical bandwidth proposed by Silverman $(1981,1986)$. In the presence of $m$ regional clubs (for example, $m=2$, rich regions and poor regions), the $f(x)$ of the data is a mixture of distributions defined by

$$
f(x)=\sum_{j=0}^{m-1} p_{j} \cdot g_{j}\left(x ; \mu_{j}, \sigma_{j}^{2}\right)
$$

where each $p_{j}$ is the proportion of each particular density, with $\Sigma p_{j}=1$, and $g_{j}$ are the densities, with first and second moments $\mathrm{m}_{j}$ and $\sigma_{j}^{2}$, respectively. For example, if we assume that the clubs are normally distributed, $g$ will be defined as follows:

$$
g_{j}\left(x ; \mu_{j}, \sigma_{j}^{2}\right)=\left(\sigma_{j}^{2} \sqrt{2 \pi}\right)^{-1} \exp \left[-\left(x-\mu_{j}\right)^{2} /\left(2 \sigma_{j}^{2}\right)\right]
$$

A critical bandwidth $h_{m}$ is defined as the minimum value of $h$ that generates a density with at least $m$ modes, which implies that for $h<h_{m}$ the estimated density function has at least $m+1$ modes. This leads to the idea of using $h_{m}$ as a statistic for evaluating:

$\mathrm{H}_{0}: f(x)$ of the regional GDP or income has $m$ modes, against $\mathrm{H}_{1}: f(x)$ has more than $m$ modes.

Thus, a high value for $h_{m}$ would indicate the presence of more than $m$ modes, rejecting the null hypothesis. The value that is considered "high" is determined through bootstrapping (see Silverman, 1981, 1986; Efron and Tibshirani, 1993). 
In general terms, the steps for implementing the test are as follows:

(i) Starting from the data, generate $B$ number of samples (denoted $x^{*}$ ) of size $n$ through bootstrapping and using the following equation:

$$
x_{i}^{*}=\bar{y}^{*}+\left(1+\frac{\hat{h}_{m}^{2}}{\hat{\sigma}^{2}}\right)^{-1 / 2}\left(y_{i}^{*}-\bar{y}^{*}+\hat{h}_{m} e_{i}\right), \quad i=1, \ldots, n
$$

where $y^{*}$ is an $n \times 1$ vector obtained from samples with replacement of the original data $(x) ; \bar{y}^{*}$ is its respective mean; $\hat{\sigma}^{2}$ is the sample variance of $x ; e_{i}$ are computergenerated standard normal variables; and $\hat{h}_{m}$ is the critical bandwidth estimator.

(ii) For each bootstrap sample $\left(x^{*}\right)$, calculate the test statistic defined as the critical bandwidth consistent with a distribution of $m$ modes ( $m$-modality) and denoted by $\hat{h}_{m}^{*}$. Denote the values of $\hat{h}_{m}^{*}$ as $\hat{h}_{m}^{*}(1), \hat{h}_{m}^{*}(2), \ldots, \hat{h}_{m}^{*}(B)$

(iii) Obtain an estimate of the achieved level of significance (ALS) of the test, defined as $N S A_{m}=\#\left\{\hat{h}_{m}^{*}(b) \geq \hat{h}_{m}\right\} / B$

(iv) The null hypothesis of $m$ modes in the density is rejected whenever $\mathrm{ALS}_{m}$ is greater than the standard levels of significance $(10 \%, 5 \%, 1 \%)$.

In short, the strategy pursued involves using this routine and applying the test beginning with the null hypothesis of $m=1$ mode. If this is not rejected, then the evaluation of multimodality is finished. If, on the other hand, the null hypothesis is rejected, then we proceed to evaluate a new null hypothesis of $m+$ 1 modes, and so on until the new hypothesis is not rejected.

\section{REFERENCES}

Andrews, D. (1991). "Heteroskedasticity and Autocorrelation Consistent Covariance Matrix Estimation." Econometrica 59(3): 817-58.

Anríquez, G., and R. Fuentes (2001). "Convergencia de producto e ingreso de las regiones en Chile: una interpretación." In Convergencia Económica e Integración: La Experiencia en Europa y América Latina, edited by T. Mancha and D. Sotelsek. Madrid: Ediciones Pirámide.

Araya, I., and C. Oyarzún (2001). "Long-Run Dynamics of Regional Growth in Chile." Revista Estudios de Economía 28(1): 69-78.

Baltagi, B., and C. Kao (2000). "Nonstationary Panels, Cointegration in Panels and Dynamic Panels: A Survey." Working paper 16. Syracuse University, Center for Policy Research.

Barro, R., and X. Sala-i-Martin (1991). "Convergence across States and Regions." Brookings Papers on Economic Activity 1: 107-82.

(1992). "Convergence." Journal of Political Economy 100(2): 223-51.

(1995). Economic Growth. Advanced Series in Economics. McGraw-Hill.

Baumol, W. (1986). "Productivity Growth, Convergence, and Welfare: What the LongRun Data Show." American Economic Review 76(5): 1072-85.

Bianchi, M. (1997). "Testing for Convergence: Evidence from Non-Parametric Multimodality Tests." Journal of Applied Econometrics 12(4): 393-409. 
Breitung, J. (2000). "The Local Power of Some Unit Root Tests for Panel Data." In Advances in Econometrics, vol. 15: Nonstationary Panels, Panel Cointegration, and Dynamic Panels, edited by B. Baltagi, p. 161-178. Amsterdam: JAI Press.

Canning, D. (1999). "Infrastructure's Contribution to Aggregate Output." Working Paper 2246. Washington: World Bank.

Cass, D. (1965). "Optimum Growth in an Aggregative Model of Capital Accumulation." Review of Economic Studies 32(3): 233-240.

Cheung, Y., and A.G. Pascual (2004). "Testing for Output Convergence: A Reexamination." Oxford Economic Papers 56(1): 45-63.

Choi, I. (2001). "Unit Root Tests for Panel Data." Journal of International Money and Finance 20(2): 249-72.

Chumacero, R. (2002). "Is There Enough Evidence against Absolute Convergence?" Working paper 176. Santiago: Central Bank of Chile.

Díaz, L., and N. Herrera (1999). "Desigualdad de ingresos y bienestar 1990-1996: análisis comparativo desde un enfoque nacional/regional." Working Paper. Santiago: MIDEPLAN.

Díaz, R., and P. Meller (2004). "Crecimiento económico regional en Chile: ¿Convergencia?”. Working Paper 180. University of Chile, Department of Industrial Engineering.

Efron, B., and R. Tibshirani (1993). "An Introduction to Bootstrap." Monographs on Statistics and Applied Probability 57. New York: Chapman and Hall.

Evans, P. (1998). "Using Panel Data to Evaluate Growth Theories.” International Economic Review 39(2): 295-306.

Fuentes, R. (1997). “¿Convergencia en las regiones en Chile? Una interpretación.” In Análisis Empírico del Crecimiento en Chile, edited by F. Morandé and R. Vergara. Santiago: Centro de Estudios Públicos/ILADES, Georgetown University.

Fujita, M., and J-F. Thisse (2002). Economics of Agglomeration. Cities, Industrial Location, and Regional Growth. Cambridge University Press.

Hadri, K. (2000). "Testing for Stationarity in Heterogeneous Panel Data." Econometric Journal 3(2): 148-161.

Im, K. S., M. Pesaran, and Y. Shin (2003). "Testing for Unit Roots in Heterogeneous Panels." Journal of Econometrics 115(1): 53-74.

Inada, K-I. (1963). "On a Two-Sector Model of Economic Growth: Comments and a Generalization." Review of Economics Studies 30: 119-127.

Koopmans, T. (1965). "On the Concept of Optimal Economic Growth.” In The Econometric Approach of Economic Planning. Amsterdam: North Holland.

Levin, A., C. F. Lin, and C. Chu (2002). "Unit Root Tests in Panel Data: Asymptotic and Finite-Sample Properties." Journal of Econometrics 108: 1-24.

Maddala, G. S., and S. Wu (1999). "A Comparative Study of Unit Root Tests with Panel Data and A New Simple Test." Oxford Bulletin of Economics and Statistics 61 (special issue): 631-652.

Morandé, F., R. Soto, and P. Pincheira (1997). "Achilles, the Tortoise, and Regional Growth in Chile." In Análisis Empírico del Crecimiento en Chile, edited by F. Morandé and R. Vergara. Santiago: Centro de Estudios Públicos/ILADES, Georgetown University.

Phillips, P. C. B., and D. Sul (2003). "The Elusive Empirical Shadow of Growth Convergence.” Discussion Paper 1398. Yale University, Cowles Foundation for Research in Economics. 
Quah, D. (1996a). "Empirics for Economic Growth and Convergence." European Economic Review 40(6): 1353-1375.

(1996b). "Ideas Determining Convergence Clubs.” Working Paper (April). London School of Economics.

(1996c). "Twin Peaks: Growth and Convergence in Models of Distribution Dynamics.” Economic Journals 106 (July): 1045-1055.

(1997). "Empirics for Growth and Distribution: Stratification, Polarization, and Convergence Clubs." Journal of Economic Growth 2(1): 27-59.

Silverman, B. (1981). "Using Kernel Density Estimates to Investigate Multimodality." Journal of the Royal Statistical Society Series B, 43.

- (1986). Density Estimation for Statistics and Data Analysis. London: Chapman and Hall.

Solow, R. (1956). “A Contribution to the Theory of Economic Growth.” Quarterly Journal of Economics 70(1): 65-94.

Soto, R., and A. Torche (2004). "Spatial Inequality after Reforms in Chile: Where Do We Stand?" Cuadernos de Economía 41: 401-424.

Swan, T. (1956). "Economic Growth and Capital Accumulation." Economic Record 32: 344-361.

White, H. (1980). "A Heteroskedasticity-Consistent Covariance Matrix and a Direct Test for Heteroskedasticity.” Econometrica 48: 817-838. 